\title{
Simulium cerqueirai, nomen novum para Simulium septentrionale Cerqueira \& Almeida, 1970 (Diptera, Sumuliidae).
}

Flávio Barbosa de Almeida

Instituto Nacional de Pesquisas

da Amoxônia
Enderlein (1935) descreveu Simulium septentrionale baseado em material procedente de "N. Russland, Murmanküste" (Norte da Rússia, Costa de Murman) e de "Lappland, Quickkjckk" (Lapônia).

Cerqueira \& Almeida (1970) usaram o mesmo nome específico para Simulium septentricnale, baseado em material proveniente do Ter. ritório Federal de Rondônia, Brasil.

As duas formas são homônimas, porém não sinônimas. Sendo necessário um nome novo para a segunda, proponho Simulium cerqueirai para S. setentrionale Cerqueira \& Almeida, 1970, preocupado por Enderlein, 1935.
O novo nome específico é uma homenagem a Nelson L. Cerqueira, pesquisador do INPA, especialista em Simuliidae e já falecido.

\section{BIBLIOGRAFIA}

Cerqueira, N. L. \& Almeida, F. B. DE

1970 - Simulidade da Amazônia. V - Descrição do Simulium septentrionale sp. $n$. (Diptera, Nematocera). Bol. INPA; Patologia Tropical, 2: 1-11.

ENDERLEIN, G.

1935 - Neue Simuliiden, besenders aus Afrika. Sitzber. Ges. naturf. Freunde. 358-64.

(Aceito para publicaçăo em 